Case study

\title{
Using seating and restricted pelvic position to improve patient functional outcomes post sarcoma removal: a case study
}

\section{O'Brien-Malone C, Harper K and Holbrook S}

Keywords sarcoma, wound healing, sitting position, occupational therapy, function

For referencing O'Brien-Malone $\mathrm{C}$ et al. Using seating and restricted pelvic position to improve patient functional outcomes post sarcoma removal: a case study. Wound Practice and Research 2020; 28(3):137-142.

DOI https://doi.org/10.33235/wpr.28.3.137-142

\section{Abstract}

Background Wound management following sarcoma removal can pose various clinical challenges. Occupational therapists support patients through positioning to allow maximum wound healing, while promoting patient function. Limited literature is available to define post-surgery seating options for this population.

Methods This timeline case study highlights the design and use of custom-made seating for a patient after an anterior left thigh sarcoma resection.

Results A modified high wedge cushion for positioning and postoperative care of the flap through management of shear, friction and pressure was provided. This incorporated seating

\section{Colleen O'Brien-Malone}

B.App Sc. (Occupational Therapy)

Occupational Therapy Department,

Sir Charles Gairdner Hospital, Perth, Australia

\section{Kristie Harper*}

BSc (OT) PGCertHlthSc (OT)

Occupational Therapy Department,

Sir Charles Gairdner Hospital, Perth, Australia

Email Kristie.Harper@health.wa.gov.au

\section{Sascha Holbrook}

BSc (OT) BBA (Business Administration)

Occupational Therapy Department,

Sir Charles Gairdner Hospital, Perth, Australia

* Corresponding author design strategies considering thigh to back angle, heel to popliteal height, stability for ischial tuberosities, sacrum and coccygeal pressure relief, patient height, width and weight. Through provision of the cushion the patient was able to engage in early sitting and maintained physical function.

Conclusion This case study highlights that design and use of custom-made seating for pressure care, wound healing and patient function can be utilised to improve patient healthcare outcomes post sarcoma removal.

\section{Key points}

What is already known

- Prolonged bed rest can lead to patient functional decline.

- Seating post sarcoma removal can pose various clinical challenges.

- There is limited published literature on the seating options available to support this patient group.

What this manuscript contributes

- Demonstrates the design and use of custom-made seating to improve a patient's functional outcomes and promote wound healing post sarcoma removal.

\section{Introduction}

Sarcomas are rare cancers that develop in bone or soft tissue ${ }^{1}$. The most effective treatment for sarcoma is surgical resection with limb salvage surgery ${ }^{1,2}$. The extent of the surgery is dependent on tumour location, size, margins, invasiveness, and involvement of vital neurovascular structures $^{3}$. Current research supports post-surgical early mobilisation and rehabilitation for these patients ${ }^{4}$. Limited literature is available on the use of custom-made pressure care cushions or seating systems to support this population. 
The hazards of bed rest during hospitalisation are well established and include new immobility ${ }^{5-7}$, accelerated bone loss $^{6}$, dehydration, malnutrition, delirium ${ }^{8,9}$, sensory deprivation ${ }^{5}$, falls ${ }^{10}$, shearing forces on the skin $^{11}$, and venous thromboembolic disease ${ }^{12-14}$. Bed rest results in a reduction of exercise capacity due to physiologic changes, including reductions in maximal stroke volume, cardiac output, and oxygen uptake ${ }^{15}$. The resulting muscle fatigue is associated with reduced muscle blood flow, red cell volume, capillarisation and oxidative enzymes ${ }^{15}$.

Providing a patient with an option to sit out of bed following surgery encourages early mobilisation, maintains physical function, reduces muscle weakness, and improves lung health and heart function ${ }^{6,16}$. It can reduce delirium ${ }^{6,17}$ and the risk of pressure injuries, and improve sleep ${ }^{6}$. Studies have found that early mobilisation is associated with shorter lengths of hospital stay ${ }^{18}$.

Post-surgery, these patients require individually designed seating that incorporates post-surgical instructions such as maintaining reduced hip flexion and appropriate tension through the flap while ensuring patient comfort. Occupational therapists need to understand the location of the wounds and graft site, type of grafting utilised, differences between wound locations, status of grafted areas - noting complications such as haematomas or slippages - and type of dressing and pressure support system in situ. Other considerations include: presence and location of oedema; concomitant injuries and surgery and impact on movement, transfers and ambulation; and comorbidities which influence blood flow, joint and general mobility or sitting balance ${ }^{19}$. Additionally, therapists need to liaise with surgeons regarding when a patient can transfer, mobilise and sit out of bed, the 'safe' ranges of motion for involved lower limb joints, including the buttocks and trunk, any pressure supports required, patient weight bearing status, and maximum time sitting out of bed.

Sitting is a dynamic activity. Seated patients should be able to lean forward and move to each side easily, using ischial tuberosities (ITs) like rockers to reposition whenever discomfort occurs. Post-surgery, a patient's ability to use seating dynamically can be compromised. Comfortable and safe seating contributes to wound healing, prevention of pressure damage, and overall function and health ${ }^{20}$. The following case study illustrates how individually designed seating can support a patient to sit out of bed following posterior left thigh sarcoma resection.

\section{Setting}

Mark (pseudonym) was seen by occupational therapy at an adult tertiary hospital in 2019. All information presented in the case study was obtained from the patient's medical record and does not present a deviation from usual data captured in the course of clinical care. Patient consent to publish the episode as an anonymous case study was sought, with written consent provided and approved by the Sir
Charles Gairdner Osborne Park Hospital Care Group Human Research Ethics Committee (2020-001).

\section{Case study}

Mark was 68 years old when admitted to hospital following a left groin arterial occlusion secondary to sarcoma with a left lower limb deep vein thrombosis (DVT). Mark's other medical history included gastro-oesophageal reflux disease, previous left DVT and insertion of an inferior vena cava (IVC) filter. He did not smoke but did drink regularly. Mark weighed $78 \mathrm{kgs}$ and was $172 \mathrm{~cm}$ in height. He was previously independent in his activities of daily living (ADL) and lived at home with his wife.

\section{Clinical journey}

Day 0

Mark underwent a wide resection of sarcoma of the left thigh. The sarcoma was located in the anterior compartment of the thigh surrounding the neurovascular bundle requiring vascular reconstruction to the left femoral vessel. He received a transverse rectus abdominis musculocutaneous (TRAM) free flap with a resulting skin defect of $12 \times 4 \mathrm{~cm}$. The right leg was utilised as a donor for a vascular graft and a thrombectomy of femoral vein was completed.

Day 2-6

Wound assessment found the flap was well perfused. Movement between $30-90^{\circ}$ of hip flexion was approved by the medical team. Mark had a Richard splint applied for ambulation secondary to left femoral nerve ligation. He was also required to utilise a full left leg stocking and bike pants. A wedged commode was provided to allow toileting without flexing the knee to $90^{\circ}$.

Overall medical governance was through an orthopaedic specialist team, but orthopaedic, plastic and vascular surgical teams were involved in this patient's care. Each of these teams concurred with the prescribed angle restrictions for the hip.

Day 7

Mark was cleared by the surgical team to commence mobilisation and weight bearing.

\section{Day 8-9}

Histopathology showed an intravascular tumour with the possibility of metastatic disease. Increased swelling of the left leg was noted, with Mark requiring surgery for evacuation of haematoma on the left wound. A debridement and washout of the wound was completed. Following this, the left leg required elevation above the level of the heart when in recumbent position but was not flexed beyond $90^{\circ}$ at the hip. Mark was able to weight bear as tolerated.

\section{Day 1-2 post-debridement and washout}

Mark was required to elevate his left leg in bed to reduce swelling as per post-surgical instructions. 


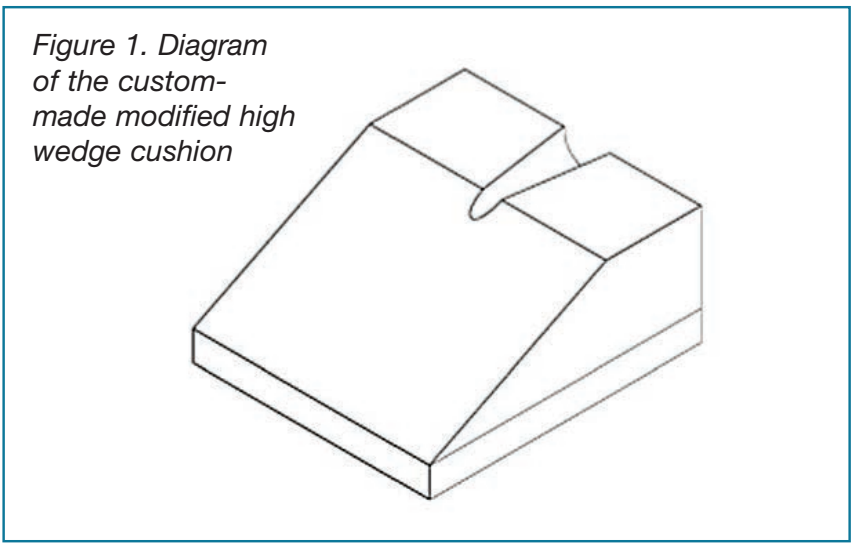

Day 4

Mark was referred to the seating and pressure care occupational therapist. Mark's left leg externally rotated when lying supine as a result of the femoral nerve ligation. A corrective positioning device was approved by the medical teams for use to realign the leg. The patient required the assistance of two therapists to sit on the edge of the bed, transfer and mobilise with a pulpit frame to a high wedge commode for personal care activities. To allow sitting, Mark was provided with a custom-made modified high wedge cushion to support sitting and improve function.

\section{Modified high wedge cushion}

As the wound and flap were sited anteriorly on the left upper thigh/groin and the blood vessel used was harvested from the right leg and grafted to the blood supply for the flap, the intention behind the open hip angle was to prevent occlusion of the newly formed blood supply and protect the vascularisation of the flap. A modified high wedge cushion was a suitable seating option to ensure the flap remained well perfused (Figure 1 \& Table 1). This was placed on a highback chair to allow maximum thoracic support (Figure 2 ). The chair was set to the correct heel-popliteal height for best transfer, ensuring that, when resting, the leg was supported on the floor with the knee in a position of extension (Table 2). The wedge cushion maintained the required sitting angle. However, a wedge without further modification potentially raises the risk of shear on the ITs and coccygeal area.

The custom-made cushion was made from Dunlop EN50250, a dense foam that prevented too much compression and therefore maintained the hip angle. The surface of the cushion was covered by a $30 \mathrm{~mm}$ upper layer of softer foam (EN36-90) to reduce the interface pressure and maximise comfort and pressure redistribution. Two options of softer top layer foam were trialled - VF60-90 and EN 36-90. Mark elected to use the Enduro foam in preference to the Viscoflex as he reported that the Viscoflex was too hard. The final cushion was inserted into a vapour-permeable fabric cover that stretched in two directions to promote best pressure distribution. The cover was tied to the chair to reduce the likelihood that the cushion would dislodge from its position.

To reduce slide, the high wedge cushion was modified by the inclusion of an 'IT shelf' which was cut into the top rear portion of the cushion allowing the femur and hip to be positioned at a manageable angle within the constraints of the allowable joint range. Contouring on the IT shelf was used to protect the coccyx from shear.

Table 1. Cushion details, including dimensions and materials

\begin{tabular}{|l|l|}
\hline Cushion details & Dimensions and materials \\
\hline Cushion width & $46 \mathrm{~cm}$ \\
\hline Cushion depth & $44 \mathrm{~cm}$ \\
\hline $\begin{array}{l}\text { Cushion height (including 3cm overlay) } \\
\text { - at front }\end{array}$ & $5 \mathrm{~cm}$ \\
\hline at rear & $18 \mathrm{~cm}$ \\
\hline IT shelf depth & $16 \mathrm{~cm}$ \\
\hline $\begin{array}{l}\text { Foam details } \\
\text { - manufacturer }\end{array}$ & Dunlop Foams \\
- grade of base foam & EN $50 / 250$ \\
\hline $\begin{array}{l}\text { Coccygeal scoop overlay } \\
\text { - width at back edge } \\
\text { - width at front edge of IT shelf }\end{array}$ & EN $36 / 90$ \\
\hline depth & $10 \mathrm{~cm}$ \\
\hline Cover details & $5 \mathrm{~cm}$ \\
\hline
\end{tabular}




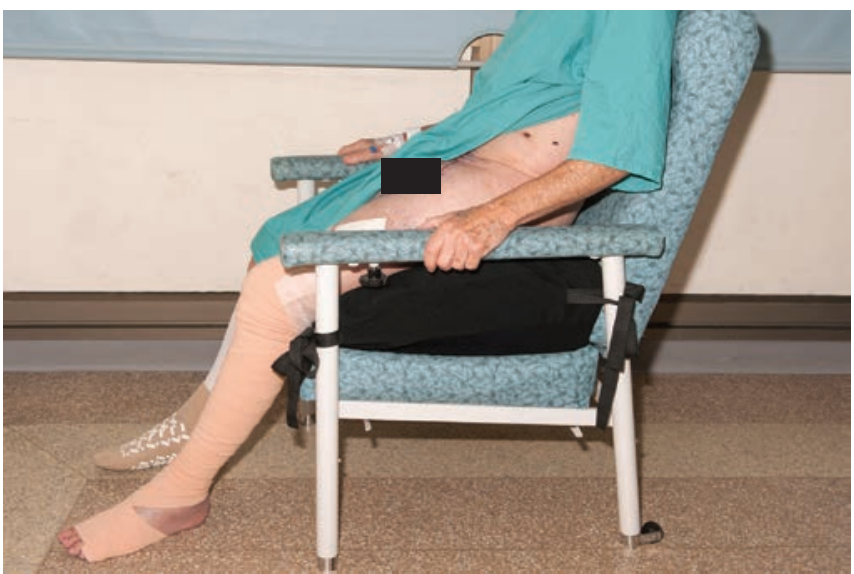

Figure 2. Positioning on a high-back chair to allow maximum thoracic support

\section{Day 5}

Mark managed to sit for 20 minutes (Figure 2) using the cushion and mobilised with a pulpit frame around the bed space. He was able to self-correct the external rotation at the left hip. Following surgery, the progression for mobilising was slow and small gains were made each day, beginning with sitting on the edge of the bed, standing up, taking one to two steps, and then being able to sit. Nursing staff viewed the wound and checked perfusion of the flap after sitting to ensure that wound and flap integrity were maintained. As tolerance to the sitting position and cushion increased and the flap health was maintained, the sitting regime progressed to 'as tolerated' up to 2 hours in accord with current clinical practice guidelines recommending limiting sitting time among the acutely ill to less than or equal to 2 hours per occasion ${ }^{21}$.

Using the McGill pain scale for measurement of pain quality ${ }^{22}$, Mark selected the descriptors of dull, pinching, pulling, annoying, flashing, burning and indicated that the present pain was steady, and that intensity was between no pain and mild pain with a numerical score of $21 / 78$.

\section{Day 7}

The IT shelf of the cushion was extended to improve the patient's sitting posture by allowing greater stability for the ITs and conformity with the lumbar support of the chair backrest.

Day 8

Mark was able to sit on the cushion at $45^{\circ}$ but reported pain and limited comfort with the high wedge; the cushion was then modified again to reduce the angle by $15^{\circ}$ to $60^{\circ}$. Mark reported no pain when seated on the lowered cushion height.

\section{Day 11}

Mark transferred to a rehabilitation facility.

Table 2. Chair and patient body anthropometric factors for consideration in seating

\begin{tabular}{|l|l|}
\hline Chair and patient body anthropometric factors & Measurements \\
\hline Hip flexion & $45^{\circ}$ \\
\hline Knee flexion & $135^{\circ}$ \\
\hline Popliteal crease to backrest & $55 \mathrm{~cm}$ \\
\hline $\begin{array}{l}\text { Seat to back angle } \\
\text { - shearing/slide evident }\end{array}$ & $\begin{array}{l}\text { at } 30^{\circ} \\
\text { at } 45^{\circ}\end{array}$ \\
\hline $\begin{array}{l}\text { Armrest height above the chair seat base } \\
24 \mathrm{~cm} \text { at the front } \\
20 \mathrm{~cm} \text { at rear }\end{array}$ \\
\hline $\begin{array}{l}\text { Seat to back angle (floor to cushion top) } \\
\text { - at the front }\end{array}$ & $45 \mathrm{~cm}$ \\
\hline Backrest height (seat to top of backrest) & $60 \mathrm{~cm}$ \\
\hline $\begin{array}{l}\text { Angles } \\
\text { Chair: }\end{array}$ & $63 \mathrm{~cm}$ \\
\hline $\begin{array}{l}\text { Cushion: } \\
\text { - without to back angle of the chair without cushion } \\
\text { - under compression }\end{array}$ & $105^{\circ}$ \\
\hline
\end{tabular}




\section{Discussion}

Ability to provide appropriate seating for a patient impacts greatly on their medical and functional outcomes and quality of life. This case study has identified the many factors that need to be considered when providing seating for patients after complex sarcoma removal. Chair and cushion design influence the patient's level of comfort, stability and functional independence. This can enable early sit-to-stand transfers and promote improved mobility ${ }^{23}$. When adding a cushion to the seat of a chair, the additional height of the cushion alters the safety of the chair by changing its centre of gravity ${ }^{24}$. This must be considered when designing the cushion and selecting the chair to be used, along with the room environment and how well the patient manages standing and sitting. If correctly adjusted, the patient expends less energy and requires less strength to complete a sit-to-stand transfer using a higher chair. Mechanical advantage reduces the effort required to transfer to/from the chair by raising the patient's centre of gravity ${ }^{25}$.

In this case study, the cushion seat width and depth were designed to fit the chair and reduce the risks associated with an additional load, altering the chair's centre of gravity. Other aspects of the chair design to consider include whether the shape and height of the backrest and armrests provide sufficient support, stability for the thick cushion, and support available for the patient to execute their sit-stand transfer.

An additional staff member was required to monitor the stability and safety of the equipment until Mark was able to sit with more control. The chair was placed with the backrest against the wall to increase the stability of the chair. Mark's early transfers were poorly controlled and were hard for him to execute. Chair stability was checked when the cushion was added and during initial transfers to ensure safety of the equipment.

Preventing shear by averting any slide down the leg slope was important for skin integrity and pressure management. These issues were handled by the use of the IT shelf, described earlier in this article, which was cut into the top rear section of the cushion. The selection of the seat angle used was based on the materials and equipment available. The chair had a significant recline on the backrest. To maintain hip flexion during transfers within the $30-90^{\circ}$ limit, the patient was prevented from sitting in a position from which he had to pull himself too far forward to recruit enough momentum and strength to stand up. When pulling himself up to a standing position, this reduced the hip angle but it remained safely within the limits set.

In this study, the patient did not find the post-surgical position comfortable as the extended leg added to the difficulty in maintaining his stability on the seat. He complained of pain in the early days and expressed a dislike for the position. Pain medications were timed to be given 30 minutes before sitting out of bed. Mark was able to hold his pelvis stable when he sat on the cushion and positioned midway between $30-60^{\circ}$. This allowed best tolerance to sitting with no evident slide while ensuring that the position of both the hip and knee were maintained at angles as specified by medical teams, and allowed for patient error.

The individually designed custom-made cushion used post-surgically reduced shear and loading through the flap. The flap was checked after each sitting to ensure it remained well-perfused. However, it is important to note that 'one wrong move' can irrevocably damage, shear or shift a graft causing graft loss. The consequences of this for patients are potentially severe, including: a return of open wounds, bleeding and more pain; the requirement for more surgery; increased risk of infection; increased likelihood of hypertrophic scarring; and long-term complications ${ }^{19}$. Because of these risks, the patient's position must be carefully monitored and he or she must be encouraged to function within a limited range of movement and not lean forward or reduce the thigh to trunk angle, although some leeway is built into this position as some leaning forward will still keep the hip flexion at less than $90^{\circ}$.

Progression to safe sitting out of bed should be rapid to reduce functional decline, maintain confidence in return to participation in normal activities of daily living and reduce hypersensitivity and/or chronic pain syndrome ${ }^{8}$. Standard practice is to have the patient resting in bed until the vascular integrity of the flap has developed. A graft will take time to develop a vascular supply and attach to the skin. If appropriate seating cannot be provided and the patient is not mobile, then patients are required to remain largely in bed, resulting in functional deterioration. The fabrication and design of the cushion creates an opportunity for the patient to sit out of bed earlier and gain the associated health benefits.

This case study demonstrates that custom-made seating can successfully achieve early sitting with reduced shear, tension or loading through the flap. Our approach utilising a custommade cushion designed to support early out of bed sitting has the potential to reduce the impost on beds, staff resources, consumables and hospital resources, by allowing the patient to return home sooner and with greater independence, thereby reducing the stress on the health system.

\section{Conclusion}

The custom-made seating described in this paper is a useful and successful intervention. It comprehensively describes the factors that need to be considered when seating a patient. The modified high wedge cushion was a viable option for positioning a hip when complex surgery restricts flexion. This innovative approach to seating may enhance patient outcomes. This case study highlights that complex surgery can significantly impact on a patient's function and that a team approach is required to reduce ADL limitations and achieve better patient-centred outcomes. 


\section{Acknowledgements}

Thanks to the patient who gave his consent for his case to be discussed in this paper.

\section{Conflict of interest}

None to declare.

\section{Funding}

The authors received no funding for this study.

\section{References}

1. McKenzie C, Barker K. Occupational therapy rehabilitation for sarcoma patients following limb salvage surgery: a scoping review. Disabil Rehabil 2019:1-13.

2. Saebye C, Fugloe HM, Nymark T, et al. Factors associated with reduced functional outcome and quality of life in patients having limb-sparing surgery for soft tissue sarcomas: a national multicenter study of 128 patients. Acta Oncologica 2017;56(2):239-44.

3. Beck LA, Einertson MJ, Winemiller MH, DePompolo RW, Hoppe KM, Sim FF. Functional outcomes and quality of life after tumorrelated hemipelvectomy. Phys Ther 2008;88(8):916-27.

4. Shehadeh A, Dahleh ME, Salem A, Sarhan Y, Sultan I, Henshaw RM, Aboulafia AJ. Standardization of rehabilitation after limb salvage surgery for sarcomas improves patients' outcome. Hematol Oncol Stem Cell Ther 2013;6(3):105-11.

5. Corcoran PJ. Use it or lose it: the hazards of bed rest and inactivity. West J Med 1991;154(5):536-8.

6. Parry SM, Puthucheary ZA. The impact of extended bed rest on the musculoskeletal system in the critical care environment. Extrem Physiol Med 2015;4:16.

7. Brown CJ, Foley KT, Lowman JD. Comparison of posthospitalization function and community mobility in hospital mobility program and usual care patients. JAMA Intern Med 2016;176(7):921-27.

8. Mattison M. Hospital management of older adults: up to date; 2019. Available from: https://www-uptodate-com.qelibresources. health.wa.gov.au/contents/hospital-management-of-olderadults?search=hospital\%20management $\% 20$ of $\% 20$ older $\% 20$ adults\&source=search_result\&selectedTitle=1 150\&usage _ type=default\&display_rank=1\#H25046837.

9. Kleinpell RM, Fletcher K, Jennings. Reducing functional decline in hospitalized elderly. In: Hughes RG, editor. Patient safety and quality: an evidence-based handbook for nurses. Rockville (MD): Agency for Healthcare Research and Quality (US); 2008.

10. Mahoney JE. Immobility and falls. Clin Geriatr Med 1998;14(4):699-726.

11. Lindgren $M$, Unosson M, Fredrikson M, Ek AC. Immobility: a major risk factor for development of pressure ulcers among adult hospitalized patients. A prospective study. Scand J Caring Sci 2004;18(1):57-64.

12. Ye F, Stalvey $\mathrm{C}$, Khuddus MA, et al. A systematic review of mobility/immobility in thromboembolism risk assessment models for hospitalized patients. J Thromb Thrombolysis 2017;44(1):94103.

13. Heit JA, Silverstein MD, Mohr DN, Petterson TM, O'Fallon WM, Melton LJ. Risk factors for deep vein thrombosis and pulmonary embolism: a population-based case-control study. Arch Intern Med 2000;160(6):809-15.
14. Liu Z, Tao X, Chen Y, Fan Z, Li Y. Bed rest versus early ambulation with standard anticoagulation in the management of deep vein thrombosis: a meta-analysis. PLoS One 2015;10(4):e0121388.

15. Convertino VA. Cardiovascular consequences of bed rest: effect on maximal oxygen uptake. Med Sci Sports Exerc 1997;29(2):191-6.

16. Kortebein P, Symons TB, Ferrando A, et al. Functional impact of 10 days of bed rest in healthy older adults. J Gerontol A Biol Sci Med Sci 2008;63(10):1076-81.

17. Falvey JR, Mangione KK, Stevens-Lapsley JE. Rethinking hospital-associated deconditioning: proposed paradigm shift. Phys Ther 2015;95(9):1307-15.

18. Pashikanti L, Von Ah D. Impact of early mobilization protocol on the medical-surgical inpatient population: an integrated review of literature. Clin Nurse Spec 2012;26(2):87-94.

19. Gupta A. Evidence summary. Lower limb split thickness skin grafts: mobilization and ambulation. The Joanna Briggs Institute EBP Database, JBI@Ovid 2016; JBI3354.

20. Beldon P. Sitting safely to prevent pressure damage. Wound Essentials 2007;2:102-4.

21. Stockton L, Gebhardt KS, Clark M. Seating and pressure ulcers: clinical practice guideline. J Tissue Viability 2009;18(4):98-108.

22. Melzack R. The McGill Pain Questionnaire: major properties and scoring methods. Pain 1975;1:277-99.

23. Hurley ST, Rutherford DJ, Hubley-Kozey C. The effect of age and seat height on sit-to-stand transfer biomechanics and muscle activation. Phys Occup Ther Geriatr 2016;34(4):169-185.

24. Stephens M, Bartley CA. Understanding the association between pressure ulcers and sitting in adults what does it mean for me and my carers? Seating guidelines for people, carers and health and social care professionals. J Tissue Viability 2018;27(1):5973.

25. Arborelius UP, Wretenberg P, Lindberg F. The effects of armrests and high seat heights on lower-limb joint load and muscular activity during sitting and rising. Ergonomics 1992;35(11):137791. 